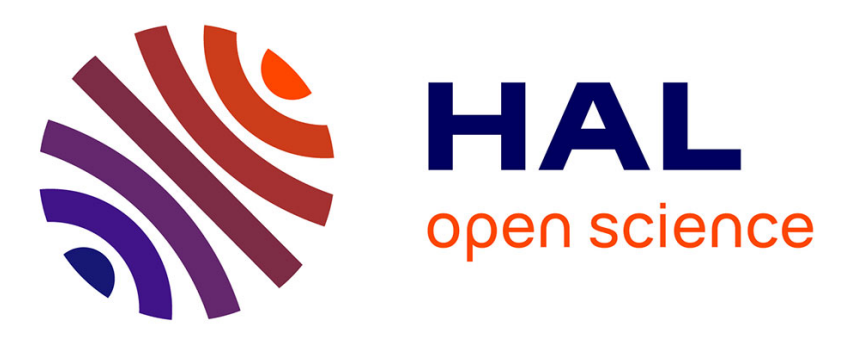

\title{
Detection of maduramycin residues in the tissues of chickens and pheasants by the screening test for antibiotic residues (STAR)
}

Ivona Kožárová, Ján Mačanga, Mária Goldová, Peter Major, Soňa Tkáčiková

\section{- To cite this version:}

Ivona Kožárová, Ján Mačanga, Mária Goldová, Peter Major, Soňa Tkáčiková. Detection of maduramycin residues in the tissues of chickens and pheasants by the screening test for antibiotic residues (STAR). Food Additives and Contaminants, 2011, pp.1. 10.1080/19440049.2011.561879 . hal00682334

\section{HAL Id: hal-00682334 \\ https://hal.science/hal-00682334}

Submitted on 25 Mar 2012

HAL is a multi-disciplinary open access archive for the deposit and dissemination of scientific research documents, whether they are published or not. The documents may come from teaching and research institutions in France or abroad, or from public or private research centers.
L'archive ouverte pluridisciplinaire HAL, est destinée au dépôt et à la diffusion de documents scientifiques de niveau recherche, publiés ou non, émanant des établissements d'enseignement et de recherche français ou étrangers, des laboratoires publics ou privés. 


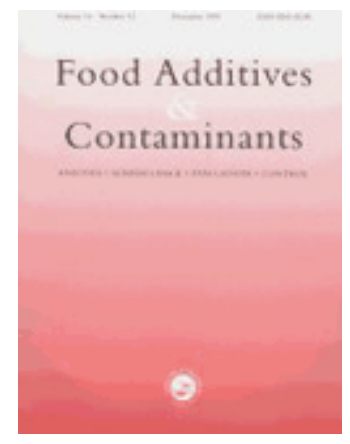

\section{Detection of maduramycin residues in the tissues of chickens and pheasants by the screening test for antibiotic residues (STAR)}

\begin{tabular}{|c|c|}
\hline Journal: & Food Additives and Contaminants \\
\hline Manuscript ID: & TFAC-2010-383.R1 \\
\hline Manuscript Type: & Original Research Paper \\
\hline $\begin{array}{r}\text { Date Submitted by the } \\
\text { Author: }\end{array}$ & 31-Jan-2011 \\
\hline Complete List of Authors: & $\begin{array}{l}\text { Kožárová, Ivona; University of Veterinary Medicine and Pharmacy in } \\
\text { Košice, Food Hygiene and Technology } \\
\text { Mačanga, Ján; University of Veterinary Medicine and Pharmacy in } \\
\text { Košice, Food Hygiene and Technology } \\
\text { Goldová, Mária; University of Veterinary Medicine and Pharmacy in } \\
\text { Košice, Parasitology } \\
\text { Major, Peter; University of Veterinary Medicine and Pharmacy in } \\
\text { Košice, Parasitology } \\
\text { Tkáčiková, Soňa; State Veterinary Institute }\end{array}$ \\
\hline Methods/Techniques: & Screening - microbial screening \\
\hline Additives/Contaminants: & Veterinary drug residues - antibiotics \\
\hline Food Types: & Animal products - meat \\
\hline
\end{tabular}

\section{SCHOLARONE ${ }^{m}$ Manuscripts}




\title{
Detection of maduramycin residues in the tissues of chickens and pheasants by the screening test for antibiotic residues (STAR)
}

\author{
Ivona Kožárová $^{1 *}$, Ján Mačanga ${ }^{1}$, Mária Goldová ${ }^{1}$, Peter Major $^{1}$, Soňa Tkáčiková $^{2}$ \\ ${ }^{1}$ University of Veterinary Medicine and Pharmacy in Košice, Komenského 73, 04181 Košice, \\ Slovakia \\ ${ }^{2}$ State Veterinary and Food Institute, Hlinkova 1, 04365 Košice, Slovakia
}

\begin{abstract}
Maduramycin is a coccidiostat authorized as a feed additive in poultry. Council Directive 96/23/EC stipulates that monitoring of foods of animal origin for residues of coccidiostats is mandatory. The aim of our study was to evaluate the STAR for the screening of maduramycin residues in the tissues of broiler chickens and pheasants. Both animal species were supplied feed medicated with Cygro $1 \%$ premix according to recommendations for use $\left(5 \mathrm{mg} . \mathrm{kg}^{-1}\right.$ of complete feed). The residues were investigated for a period of 7 days: day 0 (the last day of the administration of maduramycin), days $1-5$ (the days of the withdrawal period WP) and day 6 (the first day after elapse of the WP). According to the STAR the positivity of the sample (presence of residues of antibacterial substances) is indicated by a zone of inhibition exceeding 2 or $4 \mathrm{~mm}$ in width depending on the test organism. Maduramycin residues were detected only on the plates seeded with the test organism Bacillus stearothermophilus var. calidolactis ATCC 10149. Our results showed that there was higher potential for the presence of maduramycin residues in broiler chickens than in pheasants. All chicken tissues (muscle /thigh and breast/, gizzard, liver, heart, kidneys, spleen, lungs) were positive for maduramycin (inhibition zones $\geq 4$ $\mathrm{mm}$ ) not only throughout the withdrawal period, but even 5-day after the elapse of withdrawal period. In the case of pheasants, the positive results were detected in the gizzard, liver, heart, kidneys, spleen and lungs. On day 5 of the withdrawal period, no positive results were detected, however, on day 6 , the heart and spleen were positive again.
\end{abstract}


Keywords: microbial screening; STAR; residues; maduramycin; chickens; pheasants

\section{Introduction}

Food-producing animals are often affected by a parasitic disease called coccidiosis. Coccidiosis is caused by a single-celled protozoan organisms belonging to the genus Eimeria. This infectious disease causes serious economic consequences in the animal production without adequate control measures. Therefore coccidiostats, the drugs intended to kill or inhibit protozoa, are administered to the animals as feed additives.

Coccidiostats are authorised for use in chickens for fattening and in rabbits, and to some extent in turkeys and laying hens. According to the Regulation (EC) No 1831/2003 of the European Parliament and of the Council on additives for use in animal nutrition, only monensin, salinomycin, lasalocid, narasin, maduramycin, semduramycin (ionophoric coccidiostats) and nicarbazin, robenidine, diclazuril, halofuginone and decoquinate (chemical coccidiostats) are allowed to be used as feed additives in the European Union (EC 2003).

Administration of coccidiostats to food-producing animals leads to occurrence of unwanted residues in their tissues and products which pose a potential risk to human health (Elliot et al. 1998). To protect the health of consumers, maximum residue limits (MRLs) have been established by the Commission Regulation (EU) No 37/2010 of 22 December 2009 on pharmacologically active substances and their classification regarding MRLs in foodstuffs of animal origin for the majority of veterinary drugs (EU 2010). In the case of ionophoric coccidiostats, this regulation establishes the MRLs only for two coccidiostats: monensin (in bovine from $2 \mu \mathrm{g} \cdot \mathrm{kg}^{-1}$ in muscle, kidney and, milk to $30 \mu \mathrm{g} \cdot \mathrm{kg}^{-1}$ in liver) and lasalocid (in poultry from $20 \mu \mathrm{g} \cdot \mathrm{kg}^{-1}$ in muscle to $150 \mu \mathrm{g} \cdot \mathrm{kg}^{-1}$ in eggs).

Maduramycin is a polyether carboxylic ionophoric agent authorized according to the Commission Regulation (EC) No 2430/1999 as a coccidiostat for use in chickens for fattening at a minimum/maximum content of active substance in complete feed of $5 \mathrm{mg} \cdot \mathrm{kg}^{-1}$. The withdrawal period for maduramycin is at least 5 days prior to slaughter (EC 1999). In contrast to the established WP for maduramycin and the acceptable daily intake (ADI) of $1 \mathrm{mg} \cdot \mathrm{kg}^{-1}$, set by the 
Scientific Committee for Animal Nutrition (Scientific Opinion of the Panel on Contaminants in the Food Chain, 2008), no MRL has been derived as yet.

MRLs in foodstuffs of animal origin have to be properly controlled in accordance with the Council Directive 96/23/EC of 29 April 1996 on measures to monitor certain substances and residues thereof in live animals and animal products (EC 1996). The strategy of current residue control is based on two sequential steps, screening and confirmation. A screening method is a method used to detect the presence of a substance or class of substances at the level of interest (at or bellow their MRLs) (EC 2002).

Microbial inhibition tests (MIT) are widely used for screening of residues of pharmacologically active substances in food-producing animals and their animal products. MIT are based on inhibition of the growth of test organisms sensitive to many antibiotics and sulphonamides. Among these tests, the STAR developed at the EU Community Reference Laboratory in Fougères (France) for the screening of antimicrobial residues in milk and muscle is one of the most widely used tests in residue screening (Gaudin et al. 2004; Kožárová et al. 2009; Pikkemaat et al. 2009; Gaudin et al. 2010). The test comprises five plates: Bacillus subtilis BGA at pH 7.2 for aminoglycosides, Kocuria rhizophila ATCC 9341 at pH 8.0 for macrolides, Bacillus cereus ATCC 11778 at pH 6.0 for tetracyclines, Escherichia coli ATCC 11303 at pH 8.0 for quinolones and Bacillus stearothermophilus var. calidolactis ATCC 10149 at $\mathrm{pH} 7.4$ for betalactams and sulphonamides. The presence of an antibiotic or sulphonamide is indicated by the production of an inhibition zone around the sample.

On the basis of the results obtained in our preliminary studies (Kožárová and Máté 2000; Kožárová et al. 2002a; Kožárová 2006; Kožárová et al. 2008) and because the STAR has been officially approved for screening food-producing animals and their products for residues of veterinary drugs in Slovakia (CH 12.19. 2006), the aim of our study was to detect the presence of maduramycin residues in the tissues of broiler chickens and pheasants after oral administration in medicated feed by the STAR. The distribution and depletion of maduramycin was studied in the tissues of both animal species with respect to the day of the WP.

\section{Materials and methods}

Experimental animals and preliminary preparation of samples 
Thirty two-week-old broiler chickens (Gallus gallus, hybrid Ross) and thirty two-week-old ringnecked pheasants (Phasianus colchicus), obtained from the university farms, were used in our experiment. The animals of both animal species were randomly divided to two groups, experimental $(n=20)$ and control $(n=10)$, placed in animal-care approved cages with free access to feed and water and fed commercially produced unmedicated feed HYD-03-NORM-TYP and BŽN PLUS, respectively. The feed supplied to experimental animals was medicated with Cygro 1 $\%$ premix (Alpharma BVBA, Belgium) according to recommendations for use (5 mg. $\mathrm{kg}^{-1}$ of the active ingredient in the complete feed). All experimental animals received in-feed maduramycin for 10 days. On the last day of administration of maduramycin (day 0 of the WP), on days $1-5$ of the WP, and on the first day after elapse of the WP (day 6), two chickens and two pheasants from the experimental groups were slaughtered and the respective samples of muscle (thigh and breast), gizzard, liver, heart, kidneys, spleen, lungs were withdrawn and stored at $-20{ }^{\circ} \mathrm{C}$ until analysis. The chickens and pheasants from the control groups were slaughtered and processed in the same way. The experiment was approved by the Ethical committee of the university and carried out in the approved experimental facility at the University of Veterinary Medicine in Košice (SK 30006 P).

\section{STAR}

\section{Media}

Test agar pH 6.0 (Merck 10663, Germany), Antibiotic medium 11 (Difco 259310, USA), Test agar pH 8.0 (Merck 10664, Germany), Diagnostic Sensitive test (DST) (Oxoid CM 261, UK). Antibiotic medium 11 (Difco 259310, USA) was used instead of the originally intended Test agar pH 7.2 (Merck 15787, Germany) which is not commercially available as yet. Culture media were prepared according to the manufacture's instruction.

\section{Strains}

Bacillus subtilis BGA commercial spore suspension (Merck 10649, Germany), Kocuria rhizophila ATCC 9341 (Czech collection of microorganisms, Czech Republic), Bacillus cereus ATCC 11778 (Czech Collection of Microorganisms, Czech Republic), Escherichia coli ATCC 11303 (Czech Collection of Microorganisms, Czech Republic), Bacillus stearothermophilus var. calidolactis ATCC 10149 commercial spore suspension (Merck 1.11499, Germany). Kocuria 
rhizophila ATCC 9341, Bacillus cereus ATCC 11778 and Escherichia coli ATCC 11303 were freeze-dried cultures revived according to the instruction for reviving freeze-dried cultures delivered with the strains. Bacterial suspensions were prepared as described in the method instruction.

\section{Control standard solutions}

Streptomycin (Sigma S 6501, USA), tylosin (Sigma T 6134, USA), chlortetracycline (Sigma C 4881, USA), ciprofloxacin (Bayer RS 6661, Germany), sulphamethazine (Sigma S 5637, USA), trimethoprim (Fluka 92131, Switzerland). Control standard solutions were prepared to the final active concentrations of $2000 \mu \mathrm{g} .1^{-1}$ for streptomycin, $1000 \mu \mathrm{g} . \mathrm{l}^{-1}$ for tylosin, $200 \mu \mathrm{g} . \mathrm{l}^{-1}$ for chlortetracycline, $100 \mu \mathrm{g} . \mathrm{l}^{-1}$ for ciprofloxacin and $1000 \mu \mathrm{g} . \mathrm{l}^{-1}$ for sulphamethazine. The trimethoprim (TMP) stock solution was prepared to the concentration of $500 \mu \mathrm{g} . \mathrm{l}^{-1}$. All standard solutions were prepared and stored according to the procedures set by the method.

\section{Maduramycin standard solutions}

Maduramycin (Chemos-group, American Cyanamid Company, USA). The stock solution (500 $\mu \mathrm{g} \cdot \mathrm{ml}^{-1}$ ) of the maduramycin standard was prepared by dissolving $5 \mathrm{mg}$ of maduramycin in $10 \mathrm{ml}$ methanol (Merck, Germany). The working solutions of maduramycin were prepared by serial dilutions with sterile distilled water to the final concentration of $50 \mu \mathrm{g} . \mathrm{l}^{-1}$. Working solutions were prepared fresh prior to use.

\section{Preparation of test plates}

Antibiotic medium 11 adjusted to $\mathrm{pH} 8.0$ was seeded with ready-to-use commercial spore suspension Bacillus subtilis BGA (5 x $10^{4}$ spores.ml ${ }^{-1}$ ). Test agar $\mathrm{pH} 8.0$ was seeded with bacterial suspension Kocuria rhizophila ATCC 9341 to give a final concentration of $5 \times 10^{4}$ germs. $\mathrm{ml}^{-1}$ in the agar medium. Test agar $\mathrm{pH} 6.0$ was seeded with bacterial suspension Bacillus

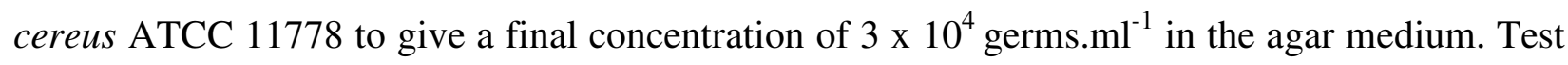
agar pH 8.0 was seeded with bacterial suspension Escherichia coli ATCC 11303 to give a final concentration of $10^{5}$ germs. $\mathrm{ml}^{-1}$ in the agar medium. DST agar adjusted to $\mathrm{pH} 7.4$ was seeded with ready-to-use commercial spore suspension Bacillus stearothermophilus var. calidolactis ATCC 10149 (5 x 10 $0^{5}$ spores.ml $\left.{ }^{-1}\right)$ and supplemented with TMP to obtain a final concentration of 
$0.005 \mu \mathrm{g} \cdot \mathrm{ml}^{-1}$ in the agar medium Finally, $5 \mathrm{ml}$ of the seeded media were transferred into Petri dishes of $90 \mathrm{~mm}$ in diameter.

\section{Quality control}

A total of $30 \mu \mathrm{l}$ of each prepared final standard solution was transferred to two filter paper discs 9 $\mathrm{mm}$ in diameter (Whatman Grade No 1, Whatman International Ltd., UK) which were placed on the surface of the corresponding agar medium: streptomycin on Antibiotic medium 11 ( $\mathrm{pH} \mathrm{8.0)}$ seeded with Bacillus subtilis BGA, tylosin on Test agar pH 8.0 seeded with Kocuria rhizophila ATCC 9341, chlortetracycline on Test agar pH 6.0 seeded with Bacillus cereus ATCC 11778, ciprofloxacin on Test agar pH 8.0 seeded with Escherichia coli ATCC 11303 and sulphamethazine on DST agar (pH 7.4) seeded with Bacillus stearothermophilus var. calidolactis ATCC 10149. Control standard solutions of antibiotics and sulphonamide were used to verify that the operating conditions were systematically respected.

\section{Determination of the detection limit (LOD) of the STAR for maduramycin}

A total of $30 \mu \mathrm{l}$ of each working solution of maduramycin was transferred to two filter paper discs, $9 \mathrm{~mm}$ in diameter (Whatman Grade No 1, Whatman International Ltd., UK), which were placed on the surface of the agar medium in Petri plates. The plates were incubated as follows: the plates seeded with Bacillus subtilis $\mathrm{BGA}$ at $30^{\circ} \mathrm{C}$ for at least $18 \mathrm{~h}$, the plates seeded with Kocuria rhizophila ATCC 9341 at $37^{\circ} \mathrm{C}$ for at least $24 \mathrm{~h}$, the plates seeded with Bacillus cereus ATCC 11778 at $30^{\circ} \mathrm{C}$ for at least $18 \mathrm{~h}$, the plates seeded with Escherichia coli ATCC 11303 at $37^{\circ} \mathrm{C}$ for at least $18 \mathrm{~h}$ and the plates seeded with Bacillus stearothermophilus var. calidolactis ATCC 10149 at $55^{\circ} \mathrm{C}$ for $12-15$ h. The lowest concentration of maduramycin standard which completely inhibited the growth and multiplication of the respective test organism of the STAR and produced an inhibition zone was considered LOD of the respective test organism of the STAR for maduramycin. Each working solution of maduramycin standard was tested in six replicates.

\section{Detection of maduramycin residues in broiler chicken and pheasant samples by the STAR}

The samples were examined as follows: a cylindrical core $8 \mathrm{~mm}$ in diameter and approximately 2 $\mathrm{cm}$ long was removed from each frozen sample using a sterile cork borer. Both ends of the 
cylindrical core were cut with a sterile lancet and discarded. Then $2 \mathrm{~mm}$ thick slices were cut from the remaining tissue. The slices were placed opposite each other in each of the five test plates. The plates were incubated according to the procedures mentioned above.

\section{Reading the test results}

After incubation, the plates were evaluated by measuring the width of clear inhibition zones around the tissue samples and the positive control discs and around the filter paper discs moistened with respective solutions of maduramycin standard with a precision of $0.01 \mathrm{~mm}$ using a digital caliper (Mitutoyo, Japan). The width of the inhibition zone was measured as the distance between the edge of the disc or the slice or the dried tissue fluid and the outer limit of the inhibition zone. The samples were considered positive if they gave the inhibition zones equal or superior to $2 \mathrm{~mm}$ in width on plates seeded with Bacillus subtilis BGA, Kocuria rhizophila ATCC 9341, Bacillus cereus ATCC 11778 and Escherichia coli ATCC 11303, and equal or superior to $4 \mathrm{~mm}$ in width on plates seeded with Bacillus stearothermophilus var. calidolactis ATCC 10149. Meat samples found to be positive by at least one of the five agar diffusion tests were considered to contain residues of antibacterial substances. The positive control paper discs should present the inhibition zones set by the method (streptomycin $4.5 \pm 1.5 \mathrm{~mm}$, tylosin $5.5 \pm$ $1.5 \mathrm{~mm}$, chlortetracycline $6.0 \pm 1.5 \mathrm{~mm}$, ciprofloxacin $5.5 \pm 1.5 \mathrm{~mm}$, sulphamethazine $5 \mathrm{piz} \pm 1.5$ $\mathrm{mm})$.

\section{Statistical analysis}

The data concerning the sizes of inhibition zones are presented as the mean \pm standard deviation (SD) of six measures. Statistical analysis was performed using software Microsoft Office Excel 2007. The levels of significance of differences between the days of the residue screening and between the tissues of both animal species were determined by the analysis of variance and $t$-test. The differences for statistical significance were judged at the levels $\mathrm{p} \leq 0.5, \mathrm{p} \leq 0.01$ and $\mathrm{p} \leq 0.001$.

\section{Confirmation of maduramycin content in animal feeds by liquid chromatography tandem mass spectrometry (LC-MS/MS)}

LC-MS/MS analysis of maduramycin in both medicated feeds was carried out according to the procedure reported in our previous study (Tkáćiková et al. 2010). However, a different sample 
preparation procedure was used for feed samples. A 10-g homogenized sample was extracted with $50 \mathrm{ml}$ of mixture methanol/deionised water $(9: 1, \mathrm{v} / \mathrm{v})$ on a horizontal shaker (IKA Labourtechnik, Germany) for $60 \mathrm{~min}$. The extract was filtered through a filter paper (Whatman Grade No 1, Whatman International Ltd., UK) and the volume of the filtrate was measured. This volume of filtrate was used to calculate the final concentration of maduramycin in the feed. A 20$\mu \mathrm{l}$ aliquot of the extract was then transferred to a 5-ml graduated flask. The flask was filled up to the mark with methanol to prepare a 250 fold dilution. A $10-\mu 1$ volume of the solution was injected to a LC-MS/MS system.

\section{Results}

The results of screening for the presence of maduramycin residues in the tissues of broiler chickens and pheasants after in-feed administration are presented in Table 1. Due to the 5-day WP, established for maduramycin, the presence of maduramycin residues was investigated on day 0 (the last day of maduramycin administration), days 1 - 5 (the days of the WP) and day 6 (the first day after elapse of the WP).

\section{$<$ Insert Table 1 around here $>$}

Table 1 shows only the mean diameters of the inhibition zones \pm SD produced by maduramycin residues around the examined chicken and pheasant tissue samples on Bacillus stearothermophilus var. calidolactis ATCC 10149 plates. No inhibition zones were observed on plates seeded with Bacillus subtilis BGA, Bacillus cereus ATCC 11778 and Escherichia coli ATCC 11303, and inhibition zones smaller than $2 \mathrm{~mm}$ were observed on plates seeded with Kocuria rhizophila ATCC 9341. The inhibition zones were recorded only around tissue samples collected from broiler chickens. The inhibition zones reached the following sizes: the liver $(0.75-1.89 \mathrm{~mm})$, the heart $(0.98-1.43 \mathrm{~mm})$, the gizzard and lungs $(<1 \mathrm{~mm})$. No inhibition zones were observed around the thigh and breast muscle, kidneys and spleen.

Bacillus stearothermophilus var. calidolactis ATCC 10149 of the STAR detected maduramycin residues in the samples of broiler chickens during the entire period of investigation. 
All chicken tissues were highly positive for maduramycin not only throughout the WP, but even on the first day following the WP. The mean diameters of the inhibition zones ranged from $4.09 \pm$ 0.37 to $11.28 \pm 1.33 \mathrm{~mm}$. The largest inhibition zones were observed on day 3 of the WP (thigh muscle $7.95 \pm 1.05 \mathrm{~mm}$, breast muscle $8.07 \pm 0.75 \mathrm{~mm}$, gizzard $6.88 \pm 1.52 \mathrm{~mm}$, liver $7.65 \pm$ $0.56 \mathrm{~mm}$, heart $6.84 \pm 0.30 \mathrm{~mm}$, spleen $8.64 \pm 0.54 \mathrm{~mm}$ ) with the exception of lungs with maximum on day $0(7.47 \pm 0.27 \mathrm{~mm})$ and kidneys with maximum on day 4 of the WP $(11.28 \pm 1.33 \mathrm{~mm})$. The largest inhibition zones were detected around the kidneys followed by the heart, spleen, thigh muscle, breast muscle, liver, lungs and, finally, gizzard.

It was interesting that we failed to observe a gradual decline in the size of inhibition zones during the WP, as shown in Figure 1. The only tissue, in which there was a gradual decline in the zones of inhibition, was the lung. In two cases (thigh and breast muscle), the inhibition zones were larger at the end of the WP than at its beginning (thigh $\mathrm{p} \leq 0.05$ ). The most significant differences in the size of inhibition zones with respect to the days of the WP were found in the liver (day $1 \mathrm{p} \leq 0.01$, day $2 \mathrm{p} \leq 0.01$, day $3 \mathrm{p} \leq 0.05$, day $4 \mathrm{p} \leq 0.05$, day $5 \mathrm{p} \leq 0.01$, day $6 \mathrm{p} \leq 0.05$ ) and less significant differences were detected in the gizzard (day $6 \mathrm{p} \leq 0.01$ ).

$<$ Insert Figure 1 around here>

Bacillus stearothermophilus var. calidolactis ATCC 10149 of the STAR detected maduramycin residues in the samples of pheasants throughout the period of investigation. Positivity was detected in the gizzard, liver, heart, kidneys, spleen and lungs. No positive results were detected on day 5 of the WP, however, on day 6, the heart and spleen were positive again. The mean diameters of the inhibition zones ranged from $1.19 \pm 0.07$ to $7.30 \pm 0.25 \mathrm{~mm}$. The largest inhibition zones were detected around the spleen followed by the heart, kidneys, gizzard, lungs, liver, thigh muscle and, finally, breast muscle.

Again, we failed to observe the gradual decline in the size of the inhibition zones during the WP, as shown in Figure 2. The increase in the size of the inhibition zones was observed up to day 1 of the WP in the heart $(5.85 \pm 0.19 \mathrm{~mm})$, up to day 2 in the thigh muscle $(3.06 \pm 0.68 \mathrm{~mm})$, breast muscle $(2.62 \pm 0.99 \mathrm{~mm})$, spleen $(7.30 \pm 0.25 \mathrm{~mm})$ and gizzard, up to day 3 of the WP in the liver $(3.65 \pm 0.28 \mathrm{~mm})$ and, at last, up to day 4 of the WP in the lungs $(4.70 \pm 0.42 \mathrm{~mm})$. A gradual decline in the size of the inhibition zones during the WP was observed only in kidneys. 
Most significant differences in the size of the inhibition zones with respect to the days of the WP were found in the spleen (day $0 \mathrm{p} \leq 0.01$, day $2 \mathrm{p} \leq 0.001$, day $3 \mathrm{p} \leq 0.001$, day $4 \mathrm{p} \leq 0.01$, day 5 $\mathrm{p} \leq 0.001$, day $6 \mathrm{p} \leq 0.001$ ) and heart (day $1 \mathrm{p} \leq 0.001$, day $2 \mathrm{p} \leq 0.05$, day $3 \mathrm{p} \leq 0.05$, day $4 \mathrm{p} \leq 0.01$, day $5 \mathrm{p} \leq 0.001$ ) and less significant differences were found in the lungs (day $5 \mathrm{p} \leq 0.05$ ).

$<$ Insert Figure 2 around here>

In comparison with pheasant tissues, all tissues of broiler chickens, except the spleen on day 2 of the WP, produced significantly greater inhibition zones throughout the period of investigation. Insignificant differences were found only between the gizzards on days 0 and 6, the spleens on day 0 , and the hearts on day 1 of the WP.

No positive results, implied by the presence of inhibition zones, were observed in the tissues of broiler chickens and pheasants obtained from maduramycin-free control groups. The inhibition zones produced on the positive control discs complied with the limit values set by the STAR.

By testing the maduramycin standard solutions, the test organism Bacillus stearothermophilus var. calidolactis ATCC 10149, in comparison with other test organisms of the STAR, showed the highest sensitivity to maduramycin. The LOD of Bacillus stearothermophilus var. calidolactis ATCC 10149 for maduramycin was $100 \mu \mathrm{g} . \mathrm{l}^{-1}$. The other test organisms, Bacillus cereus ATCC 11778, Kocuria rhizophila ATCC 9341 and Bacillus subtilis BGA, were much less sensitive. The LODs of these respective test organisms for maduramycin were several times higher. Escherichia coli ATCC 11303 showed no sensitivity to maduramycin. The mean diameters of the inhibition zones $(\mathrm{mm} \pm \mathrm{SD})$ produced by the working solutions of maduramycin standard on the plates seeded with Bacillus stearothermophilus var. calidolactis ATCC 10149 are presented in Table 2. The results obtained support the data reported in our previous study (Kožárová et al. 2008).

$<$ Insert Table 2 around here $>$

Both feed samples were analyzed by LC-MS/MS to check whether the assumed concentration level of maduramycin was obtained. The detection was performed on a triple quadrupole mass spectrometer in multiple reaction monitoring (MRM) mode after ionisation in 
the positive electrospray ionisation mode. Analysis by LC-MS/MS confirmed the presence of maduramycin in both medicated feeds. The concentrations of maduramycin did not exceed the maximum content of the active substance in complete feed $\left(5 \mathrm{mg} \cdot \mathrm{kg}^{-1}\right)$. The calibration curve of maduramycin standard and the MRM chromatograms of maduramycin standard and the sample of feed medicated with Cygro $1 \%$ premix are presented in Figures 3-5. No maduramycin was detected in both unmedicated feeds.

$<$ Insert Figure 3 around here>

$<$ Insert Figure 4 around here>

$<$ Insert Figure 5 around here $>$

\section{Discussion}

The presence of contaminants and residues of veterinary medicinal products in foodstuffs is a matter of public concern (Danko et al. 2005; Lukáč and Massányi 2007; Cháfer-Pericás et al. 2010). In order to protect public health, MRLs should be established in accordance with generally recognised principles of safety assessment, taking into account toxicological risks, environmental contamination, as well as the microbiological and pharmacological effects of residues. MRLs are the points of reference for the establishment of withdrawal periods in marketing authorisations for veterinary medicinal products to be used in food-producing animals as well as for the control of residues in food of animal origin (EC 2009a).

Council Directive 96/23/EC describes guidelines for the official control of residues of pharmacologically active substances in food of animal origin. It divides all pharmacologically active substances into two groups, group A and group B. Coccidiostats belong to the group B $2 \mathrm{~b}$ and they should be detected in bovine, ovine, caprine, porcine and equine animals, poultry, eggs, rabbit meat and the meat of wild game and farmed game (EC 1996).

Maduramycin is a polyether ionophoric coccidiostat authorised for prevention of coccidiosis in fattening chickens. It is added to the feed in the form of ammonium salt at a minimum/maximum content of active substance in complete feed of $5 \mathrm{mg} \mathrm{kg}^{-1}$ and should be 
withdrawn 5 days before slaughter. The WP established for maduramycin should ensure decline of its residues in the tissues of broiler chickens to the safe residue level. Because maduramycin has no MRL established for chicken tissues, it is questionable which maximum concentration of maduramycin resulting from its use as feed additive may be recognized to be safe in or on the food.

Data on the monitoring of veterinary medicinal product residues and other substances in food of animal origin in the Member States suggest that the human consumer may be exposed to residues of coccidiostats through the consumption of poultry meat and eggs (Technical report of EFSA, 2010). Several analytical approaches have been used to determine the coccidiostat residues in poultry tissues and eggs (Kennedy et al. 1997; Shen et al. 2001; Kožárová et al. 2002b; Dubois et al. 2004; Rokka and Peltonen, 2006; Dubreil-Chéneau et al. 2009; Olejnik et al. 2009; Shao et al., 2009; Stubbings and Bigwood, 2009; Tkáčiková et al. 2010), but only a few screening methods based on microbial inhibition have been used to detect their presence in poultry tissues (Kožárová et al. 2002a; Prieto et al. 2003; Aila et al. 2006; Shitandi et al. 2006; Li 2007; Kožárová et al. 2008; Shitandi et al. 2008).

The results obtained in our previous studies showed: 1) the sensitivity of the test organism Bacillus stearothermophilus var. calidolactis to the ionophoric coccidiostats, including maduramycin (Kožárová and Máté 2000; Kožárová 2006); 2) tissue samples of he experimental broiler chickens receiving in-feed monensin and maduramycin showed positive responses on the plates seeded with Bacillus stearothermophilus var. calidolactis (Kožárová et al. 2002a; Kožárová et al. 2008); 3) by using the HPLC and LC-MS/MS techniques, the residues of both coccidiostats in the positive samples were identified and quantified (Kožárová et al. 2002b, Tkáčiková et al. 2010). The LC-MS/MS method allowed us to detect residues of maduramycin in all examined tissue samples of broiler chickens (heart, muscle, kidneys, liver, gizzard and skin) on the last day of the WP.

Considering the results obtained in our studies mentioned above and because the STAR is the only plate agar diffusion method officially approved for screening food-producing animals and their products for residues of veterinary drugs in Slovakia, we focused our study on detection of maduramycin residues in the tissues of broiler chickens and pheasants after oral administration in medicated feed by the STAR method. The maduramycin residues were investigated throughout 
the 5-day WP established for maduramycin, and also on day 6, representing the first day following the WP.

The result was considered positive if an inhibition zone exceeding 2 or $4 \mathrm{~mm}$ in width was produced on at least one of the five plates. The positive results were obtained only on Bacillus stearothermophilus var. calidolactis ATCC 10149 plates. The STAR detected maduramycin residues in all examined tissues of broiler chickens up to day 6 and all these tissues were found positive throughout the period of investigation. The largest inhibition zones were observed in the kidneys followed by the heart, spleen, thigh muscle, breast muscle, liver, lungs and, finally, gizzard. Our results showed that there is a high potential for the presence of maduramycin residues in broiler chickens.

Less positive results were obtained in pheasants. The gizzard, liver, heart, kidneys, spleen and lungs were considered positive up to day 4 of the WP. No positive results were detected in the thigh muscle and breast muscle. The largest inhibition zones were produced by the spleen followed by the heart, kidneys, gizzard, lungs, liver, thigh muscle and, finally, breast muscle. It was interesting that the spleen and heart appeared positive also on the last day of maduramycin residue investigation. Less positive results obtained in pheasants could be attributed to the differences in chemical composition of meat and lower proportion of fat (Suchý et al. 2002; Tucák et al. 2008).

The size of the inhibition zone is directly proportional to the concentration of the antibacterial substance within a concentration range specific for each substance. The results obtained in our studies showed that the LOD of maduramycin for Bacillus stearothermophilus var. calidolactis ATCC 10149 of the STAR is $100 \mu \mathrm{g} \cdot \mathrm{l}^{-1}$ (mean inhibition zone $3.01 \pm 0.71 \mathrm{~mm}$ ). In our opinion the concentration of maduramycin residues in the positive tissue samples should be higher than $200 \mu \mathrm{g} \cdot \mathrm{kg}^{-1}$ (mean inhibition zone $3.69 \pm 0.72 \mathrm{~mm}$ ). Because no MRL has been established for maduramycin in edible chicken tissues our evaluation regarding food safety issues was based on MRL of 400-500 $\mu \mathrm{g} . \mathrm{kg}^{-1}$, established for maduramycin in some countries (USA, Canada, Japan). Maduramycin, at the residual concentration of $500 \mu \mathrm{g} \cdot \mathrm{kg}^{-1}$, formed an inhibition zone of $6.09 \pm 0.81 \mathrm{~mm}$ in diameter. The diameters of the inhibition zones detected on the first day following the WP showed that maduramycin residues in the tissues of broiler chickens may exceed the non-EU established MRL. The only limit set today for maduramycin in food of animal origin from the animal species other than chickens for fattening and turkeys, originating from the 
non-target feed concerned, is the maximum level of $2 \mu \mathrm{g} \cdot \mathrm{kg}^{-1}$ established by the Commission Regulation (EC) No 124/2009 (EC 2009b).

Our results allowed us to state that the establishment of EU MRL for maduramycin in chicken tissues is essential to reduce the risk to consumer's health from the ingestion of maduramycin residues in poultry products and to ensure that the edible chicken tissues are free from maduramycin residues after the elapse of the WP. To find if such tissues are really free from maduramycin residues, all samples showing positive responses must be subjected to further investigation by a specific confirmatory method enabling the substance to be unequivocally identified and, if necessary, quantified at the level of interest (EC 2002).

\section{Conclusions}

An inhibition test is useful for the detection of an antibacterial substance if LOD of this substance is at the level of interest. The level of interest means the concentration of substance in the sample that is significant for determination of its compliance with relevant legislative provisions (EU, 2002). Because no MRL has been established for maduramycin it is not possible to conclude whether the STAR can be considered a reliable method for detection of maduramycin residues at the level of interest. Our results showed that the STAR may have a potential for the use as a screening test for maduramycin residues in the tissues of broiler chickens and pheasants. The test organism Bacillus stearothermophilus var. calidolactis ATCC 10149 showed higher sensitivity for maduramycin by detecting positive results in both animal species. The STAR is applicable for a broad-spectrum detection of antibiotic residues and, as seen from our study, Bacillus stearothermophilus var. calidolactis ATCC 10149 seems to be a suitable test organism for the screening of the presence of maduramycin residues in poultry.

\section{Acknowledgements}

This study was supported by VEGA grants No 1/0403/08, No 1/0658/09 and No 1/0144/10.

\section{References}

Aila O, Shitandi A, Mahungu S. 2006. Detection of furazolidone residues in chicken tissues and serum using a low cost microbiological methods. In: Proceedings of the 10th Kari Bienial Scientific Conference "Responding to demands and opportunities through innovative 
agricultural technologiesknowledge and approaches". Kenya Agricultural Research Institute, Nairobi, November 12-17, 2006. p. 1-6. Available at: http://www.kari.org/fileadmin/publications/10thproceedings/Volone/Detection_Furazol.pdf.

$\mathrm{CH}$ 12.19. 2006. Screening test for determination of antibiotic residues using bacterial strains (STAR). In: List of official methods for laboratory diagnostics of food and feed. Bulletin of the Ministry of Agriculture of the Slovak Republic, vol. 38. p. 68-81.

Cháfer-Pericás C, Maquieira Á, Puchades R. 2010. Fast screening methods to detect antibiotic residues in food samples. Trends Anal Chem. 29:1038-1049.

Danko J, Lešník F, Jenča A. 2005. Xenobiotics and their relation to health. Košice: University of Veterinary Medicine. p. 107.

Dubois M, Pierret G, Delahaut Ph. 2004. Efficient and sensitive detection of residues of nine coccidiostats in egg and muscle by liquid chromatography-electrospray tandem mass spectrometry. J Chromatogr B. 813:181-189.

Dubreil-Chéneau E, Bessiral M, Roudaut B, Verdon E, Sanders P. 2009. Validation of a multiresidue liquid chromatography-tandem mass spectrometry confirmatory method for 10 anticoccidials in eggs according to Commission Decision 2002/657/EC. J Chromatogr A. 46:8149-8157.

Elliot ChT, Kennedy DG, McCaughey WJ. 1998. Methods for the detection of polyether ionophore residues in poultry. Analyst. 123:45-56.

EC 1996. Council Directive 96/23/EC of 29 April 1990 establish on measures to monitor certain substances and residues thereof in live animals and animal products. Off $\mathbf{J}$ Eur Commun. L125:10-32.

EC 1999. Commission Regulation (EC) No 2430/1999 of 16 November 1999 linking the authorisation of certain additives belonging to the group of coccidiostats and other medicinal substances in feedingstuffs to persons responsible for putting them into circulation. Off J Eur Commun. L296, 3-11.

EC 2002. Commission Decision 2002/657/EC of 12 August 2002 implementing Council Directive 96/23/EC concerning the performance of analytical methods and the interpretation of results. Off J Eur Commun. L221:8-28.

EC 2003. Regulation (EC) No 1831/2003 of the European Parliament and of the Council of 22 September 2003 on additives for use in animal nutrition. Off J Eur Commun. L268:29-43. 
EC 2009a. Regulation (EC) No 470/2009 of the European Parliament and of the Council of 6 May 2009 laying down Community procedures for the establishment of residue limits of pharmacologically active substances in foodstuffs of animal origin, repealing Council Regulation (EEC) No 2377/90 and amending Directive 2001/82/EC of the European Parliament and of the Council Regulation (EC) No 726/2004 of the European Parliament and the Council. Off J Eur Commun. L152:11-22.

EC 2009b. Commission Regulation (EC) No 124/2009 of 10 February 2009 setting maximum levels for the presence of coccidiostats or histomonostats in food resulting from unavoidable carry-over of these substances in non target feed. Off J Eur Commun. L40:7-11.

EU 2010. Commission Regulation (EU) No 37/2010 of 22 December 2009 on pharmacologically active substances and their classification regarding maximum residue limits in foodstuffs of animal origin. Off J Eur Union L15:1-72.

Gaudin V, Maris P, Fuselier R, Ribouchon JL Cadieu N, Rault A. 2004. Validation of a microbiological method: the STAR protocol, a five-plate test, for the screening of antibiotic residues in milk. Food Addit Contam. 21:422-433.

Gaudin V, Hedou C, Rault A, Verdon E. 2010. Validation of a Five Plate Test, the STAR protocol, for the screening of antibiotic residues in muscle from different animal species according to European Decision 2002/657/EC. Food Addit Contam A. 27: 935-952.

Kennedy DG, Blanchflower WJ, O’Dornan BC. 1997. Development of an ELISA for maduramicin and determination of the depletion kinetics of maduramicin residues in poultry. Food Addit Contam. 14:27-33.

Kožárová I, Máté D. 2000. Evaluation of the sensitivity of individual test organisms to residual concentrations of selected types of anticoccidial drugs. Bull Vet Inst Pulawy. 44:187-192.

Kožárová I, Máté D, Cabadaj R, Różańska H, Hussein K, Laciaková A. 2002a. An evaluation of the microbiological diffusion methods as a tool for screening monensin residues in the tissues of broiler chickens. Folia Vet. 46:27-33.

Kožárová I, Tkáčiková S, Máté D, Cabadaj R, Hussein K, Neuschl J, Zaborskiene G. 2002b. An evaluation of the high-performance liquid chromatography method for determining monensin residues in the tissues of broiler chickens. Folia Vet. 46:189-193. 
Kožárová I. 2006. Comparison study of detection sensitivity of microbial inhibition tests to anticoccidials. In: Proceeding Book of 6th International Scientific Conference on risk factors in the food chain. Slovak University of Agriculture, Nitra, October 12, 2006. p. 189-193.

Kožárová I, Sýkorová Goffová Z, Máté D. 2008. Detection of maduramycin residues in the tissues of broiler chicken by using the Premi ${ }^{\circledR}$ Test and the STAR. Slovak J Anim Sci. 41:206.

Kožárová I, Janošová J, Máté D, Tkáčiková S. 2009. Evaluation of different microbial inhibition tests for the detection of sulphamethazine residues in the edible tissues of rabbits. Food Addit Contam A. 26:978-987.

Li N. 2007. Progress on Polyether Antibiotics Residue Analysis. Poult Sci. 5:38-40.

Lukáč N, Massányi P. 2007. Effects of trace elements on the immune system. Epidemiol Mikrobiol Imunol. 56:3-9.

Olejnik M, Szprengier-Juszkiewicz T, Jedziniak P. 2009. Multi-residue confirmatory method for the determination of twelve coccidiostats in chicken liver using liquid chromatography tandem mass spectrometry. J Chromatogr A. 1216:8141-8148.

Pikkemaat MG, Rapallini MLBA, Oostra-van Dijk S, Elferink AJW. 2009. Comparison of three microbial screening methods for antibiotics using routine monitoring samples. Anal Chim Acta. 637: 298-304.

Prieto N, Castro LJ, Mora MJ, Lavin P, Mantecón AR. 2003. Optimización de un método microbiológico para la detección de monensina sódica en pieso. ITEA. 24: 750-752.

Rokka M, Peltonen K. 2006. Simultaneous determination of four coccidiostats in eggs and broiler meat: Validation of an LC-MS/MS method. Food Addit Contam. 23:470-478.

Scientific Opinion of the Panel on Contaminants in the Food Chain. 2008. Cross-contamination of non-target feedingstuffs by maduramicin authorised for use as a feed additive. EFSA J. 594:1-30.

Shao B, Wu X, Zhang J, Duan H, Chu X, Wu Y. 2009. Development of a Rapid LC-MS-MS Method for Multi-Class Determination of 14 Coccidiostat Residues in Eggs and Chicken. Chromatographia. 69:1083-1088.

Shen J, Qian C, Jiang H, Yang H. 2001. Development of an enzyme-linked immunosorbent assay for determination of maduramicin in broiler chicken tissues. J Agric Food Chem. 49:26972701. 
Shitandi A, Oketch A, Mahungu S. 2006. Evaluation of a Bacillus stearothermophilus tube test as a screening tool for anticoccidial residues in poultry. J Vet Sci. 7:177-180.

Shitandi A, Aila O, Ottaro S, Aliong'o L, Mwangi G, Kumar-Sharma H, Matofari J. 2008. Effect of deep frying on furazolidone anticoccidial drug residues in liver and muscle tissues of chicken. Afr J Food Sci. 2:144-148.

Stubbings G, Bigwood T. 2009. The development and validation of multiclass liquid chromatography tandem mass spectrometry (LC-MS/MS) procedure for the determination of veterinary drug residues in animal tissue using QuEChERS (QUick, Easy, CHeap, Effective, Rugged and Safe) approach. Anal Chim Acta. 637:68-78.

Suchý P, Jelínek P, Straková E, Hucl J. 2002. Chemical composition of muscles of hybrid broiler chickens during prolonged feeding. Czech J Anim Sci. 47:511-518.

Technical report of EFSA. 2010. Report for 2008 on the results from the monitoring of veterinary medicinal product residues and other substances in food of animal origin in the Member States. EFSA J. 8:1-55.

Tkáčiková S, Kožárová I, Máté D. 2010. Liquid chromatography tandem mass spectrometry determination of maduramycin residues in the tissues of broiler chickens. Food Addit Contam A. 27:1226-1232.

Tucak Z, Škrivanko M, Posavčević Š, Perškić M, Bošković I, Jumić V. 2008. The influence of keeping pheasants in captivity vs. nature on the biological value of meat and its use in human nutrition. Coll Antropol. 32:959-962. 
Table 1. Mean diameters of inhibition zones $(\mathrm{mm} \pm \mathrm{SD})$ observed at the screening for maduramycin residues in the tissues of broiler chickens and pheasants using the STAR with Bacillus stearothermophilus var. calidolactis ATCC 10149 at pH 7.4.

\begin{tabular}{|c|c|c|c|c|c|c|c|c|c|c|c|c|c|c|c|}
\hline & \multirow{3}{*}{$\begin{array}{c}\text { Matrices } \\
\text { Thigh }\end{array}$} & \multicolumn{14}{|c|}{ Day of WP } \\
\hline & & \multicolumn{2}{|l|}{0} & \multicolumn{2}{|l|}{1} & \multicolumn{2}{|l|}{2} & \multicolumn{2}{|c|}{3} & \multicolumn{2}{|l|}{4} & \multicolumn{2}{|l|}{5} & \multicolumn{2}{|l|}{6} \\
\hline \multirow{8}{*}{ 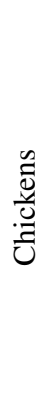 } & & $5.53 \pm 0.29$ & +++ & $6.05 \pm 0.15$ & $+++; *$ & $6.84 \pm 0.12$ & $+++; * * *$ & $7.95 \pm 1.05$ & ++ & $8.04 \pm 0.11$ & +++ & $7.38 \pm 0.57$ & +++ & $6.09 \pm 0.41$ & $+++; * *$ \\
\hline & Breast & $4.44 \pm 0.22$ & +++ & $4.57 \pm 0.28$ & $+++; * *$ & $5.62 \pm 0.47$ & $++; * *$ & $8.07 \pm 0.75$ & +++ & $7.21 \pm 0.33$ & +++ & $6.04 \pm 0.44$ & $+++; * *$ & $5.00 \pm 0.73$ & +++ \\
\hline & Gizzard & $5.44 \pm 0.52$ & & $5.42 \pm 0.37$ & ++ & $5.02 \pm 0.47$ & + & $6.88 \pm 1.52$ & ++ & $5.88 \pm 0.44$ & +++ & $5.55 \pm 0.24$ & +++ & $4.09 \pm 0.37$ & $+; * *$ \\
\hline & Liver & $7.17 \pm 0.34$ & +++ & $5.92 \pm 0.07$ & $+++; * *$ & $6.58 \pm 0.18$ & $+++; * *$ & $7.65 \pm 0.56$ & $+++; *$ & $6.68 \pm 0.17$ & $+++; *$ & $5.45 \pm 0.31$ & $+++; * *$ & $4.84 \pm 0.21$ & $+++; *$ \\
\hline & Heart & $7.83 \pm 1.15$ & ++ & $6.23 \pm 0.54$ & + & $6.72 \pm 0.80$ & ++ & $8.91 \pm 0.37$ & $+++; * *$ & $6.84 \pm 0.30$ & $+++; * * *$ & $6.24 \pm 0.51$ & +++ & $5.56 \pm 0.54$ & ++ \\
\hline & Kidneys & $8.28 \pm 0.35$ & ++ & $7.62 \pm 0.46$ & $+++; *$ & $10.53 \pm 1.48$ & ++ & $10.17 \pm 0.29$ & +++ & $11.28 \pm 1.33$ & +++ & $8.41 \pm 0.52$ & $+++; * *$ & $7.12 \pm 0.29$ & $+++; * *$ \\
\hline & Spleen & $6.71 \pm 1.60$ & & $6.72 \pm 0.11$ & +++ & $6.69 \pm 0.06$ & $* *$ & $8.64 \pm 0.54$ & +++ & $8.49 \pm 0.73$ & +++ & $7.67 \pm 0.13$ & +++ & $6.64 \pm 0.62$ & $++; *$ \\
\hline & Lungs & $7.47 \pm 0.27$ & +++ & $6.59 \pm 0.33$ & $++; * *$ & $6.43 \pm 0.27$ & +++ & $6.96 \pm 0.27$ & $+++; *$ & $6.66 \pm 0.29$ & +++ & $6.44 \pm 0.22$ & +++ & $4.99 \pm 0.58$ & $++; * *$ \\
\hline \multirow{8}{*}{ 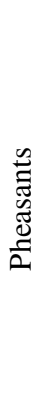 } & Thigh & $3.25 \pm 0.16$ & & $3.40 \pm 0.29$ & & $3.06 \pm 0.68$ & & $2.82 \pm 0.23$ & & $2.43 \pm 0.07$ & $*$ & $1.19 \pm 0.07$ & $* * *$ & $2.57 \pm 0.27$ & $* *$ \\
\hline & Breast & $2.21 \pm 0.01$ & & $1.94 \pm 0.15$ & $*$ & $2.62 \pm 0.99$ & & $2.47 \pm 0.61$ & & $2.22 \pm 0.05$ & & $1.41 \pm 0.51$ & $*$ & $1.76 \pm 0.28$ & \\
\hline & Gizzard & $4.66 \pm 1.61$ & & $2.43 \pm 1.16$ & & $4.64 \pm 0.79$ & $*$ & $3.58 \pm 1.00$ & & $2.76 \pm 0.75$ & & $3.47 \pm 0.15$ & & $3.69 \pm 0.06$ & * \\
\hline & Liver & $3.72 \pm 0.30$ & & $3.79 \pm 0.25$ & $* * *$ & $2.59 \pm 0.23$ & $* *$ & $3.65 \pm 0.28$ & & $3.53 \pm 0.28$ & & $2.27 \pm 0.09$ & $* *$ & $3.63 \pm 0.30$ & $* *$ \\
\hline & Heart & $3.29 \pm 0.36$ & & $5.85 \pm 0.19$ & $* * * *$ & $4.96 \pm 0.53$ & $*$ & $3.75 \pm 0.28$ & $*$ & $4.97 \pm 0.02$ & $* *$ & $3.00 \pm 0.22$ & $* * *$ & $3.77 \pm 0.62$ & \\
\hline & Kidneys & $5.59 \pm 0.04$ & & $4.52 \pm 0.17$ & $* * * *$ & $4.02 \pm 0.06$ & $* *$ & $3.59 \pm 0.13$ & $* *$ & $3.92 \pm 0.87$ & & $2.91 \pm 0.38$ & & $3.01 \pm 0.27$ & \\
\hline & Spleen & $6.28 \pm 0.21$ & & $5.62 \pm 0.04$ & $* *$ & $7.30 \pm 0.25$ & $++; * * *$ & $5.54 \pm 0.34$ & **** & $4.02 \pm 0.11$ & ** & $3.01 \pm 0.22$ & $* * *$ & $4.88 \pm 0.07$ & $* * *$ \\
\hline & Lungs & $4.19 \pm 0.02$ & & $3.98 \pm 0.69$ & & $3.96 \pm 0.36$ & & $4.17 \pm 0.38$ & & $4.70 \pm 0.42$ & & $3.28 \pm 0.67$ & $*$ & $2.88 \pm 0.38$ & \\
\hline
\end{tabular}

Bold numerals indicate positive results.

${ }^{+}$Comparison between chicken and pheasant tissues.

${ }^{*}$ Comparison between the days of residue screening in chickens and pheasants, respectively.

${ }^{+}(*)-\mathrm{p} \leq 0.5$.

$++(* *)-\mathrm{p} \leq 0.01$.

$+++(* * *)-\mathrm{p} \leq 0.001$. 
Table 2. The mean diameters of the inhibition zones $(\mathrm{mm} \pm \mathrm{SD})$ produced by the working solutions of maduramycin standard on the plates seeded with Bacillus stearothermophilus var. calidolactis ATCC 10149 at ph 7.4.

\begin{tabular}{ccccccc}
\hline \multirow{2}{*}{ STAR/Plate } & \multicolumn{5}{c}{ Concentration of maduramycin $\left(\mu \mathrm{g} .1^{-1}\right)$} \\
\cline { 2 - 6 } & $\mathbf{1 0 0}$ & 200 & 300 & 400 & 500 \\
\hline Bst ATCC 10149 & $3.01 \pm 0.71$ & $3.69 \pm 0.72$ & $4.19 \pm 0.34$ & $5.04 \pm 0.52$ & $6.09 \pm 0.81$ \\
\hline
\end{tabular}

Notes: The concentration in bold font represents the LOD of Bacillus stearothermophilus var. calidolactis ATCC 10149 of the STAR for maduramycin.

Bst, Bacillus stearothermophilus var. calidolactis. 


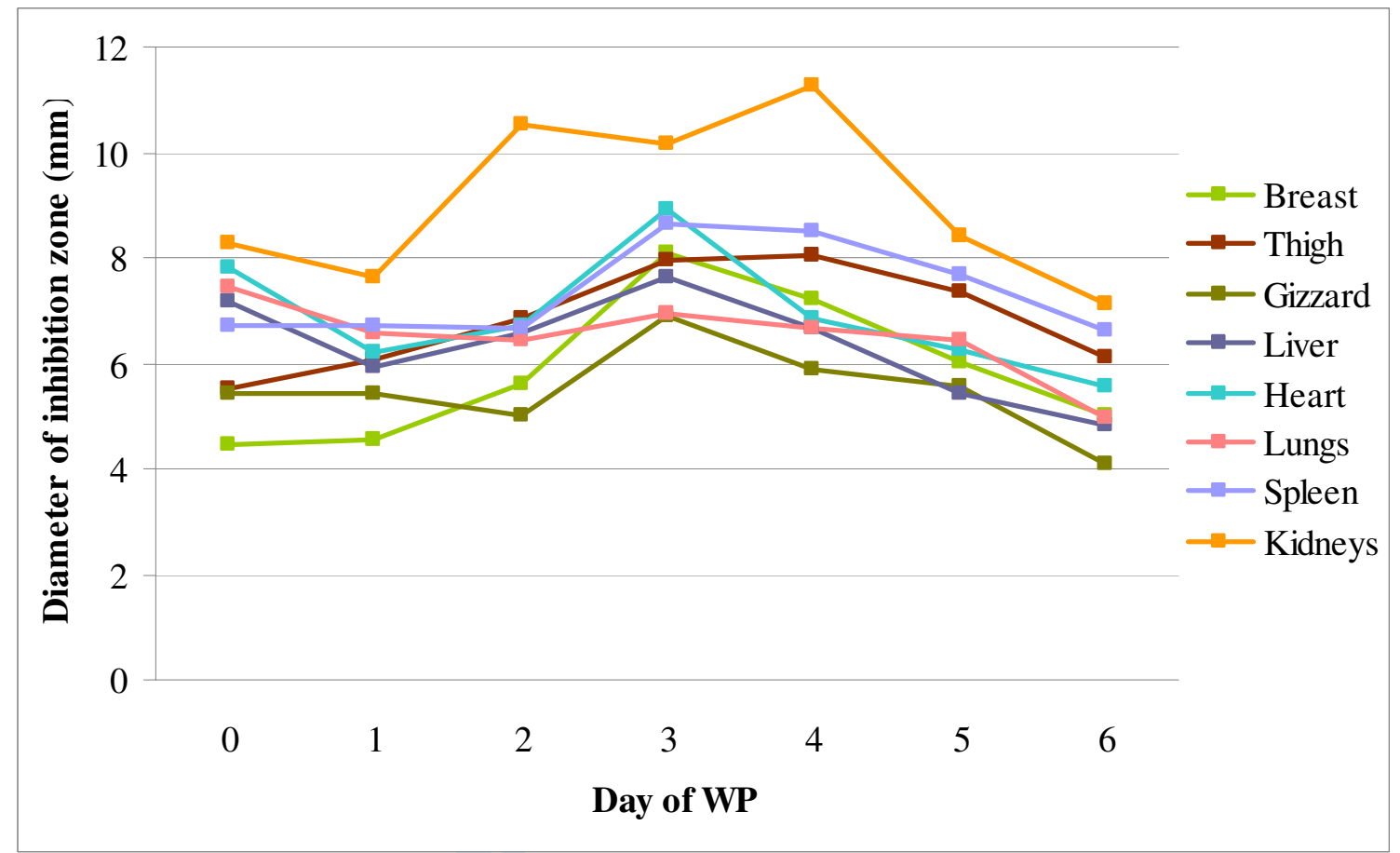

Figure 1. Comparison of the mean diameters of the inhibition zones produced by maduramycin residues in the samples of chickens. 


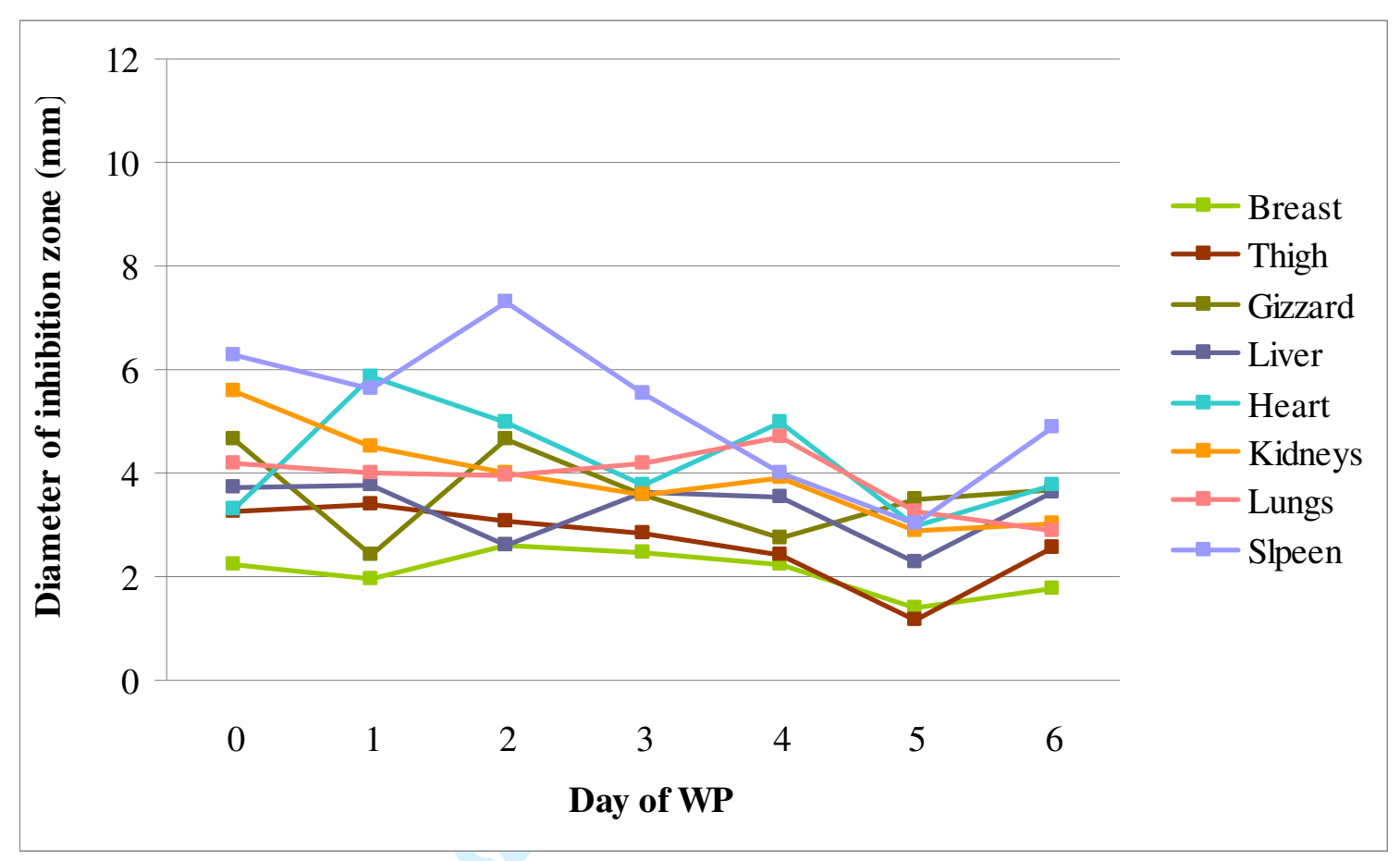

Figure 2. Comparison of the mean diameters of the inhibition zones produced by maduramycin residues in the samples of pheasants. 


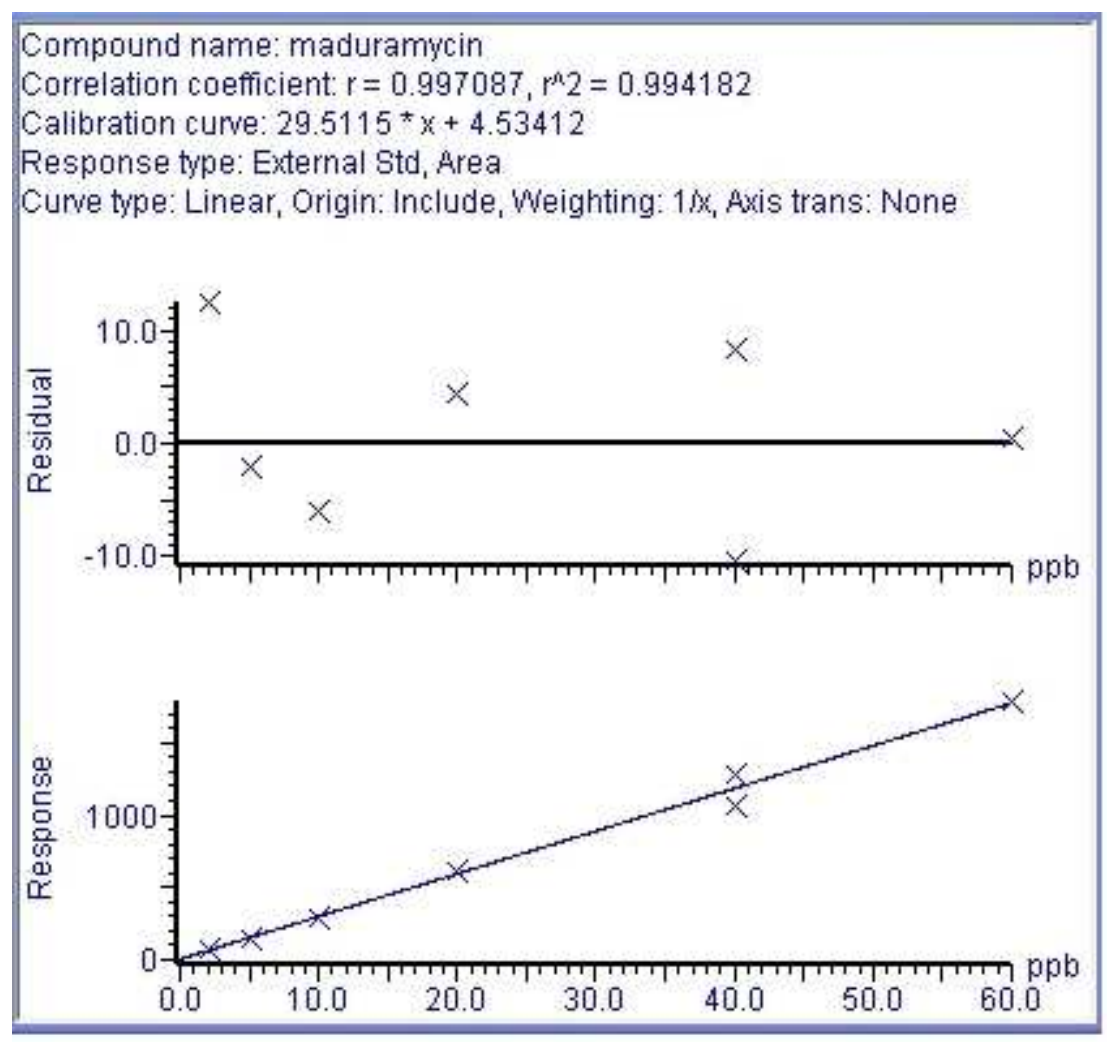

Figure 3. Calibration curve of maduramycin standard at the concentration range of $2-60$ $\mu \mathrm{g} \cdot \mathrm{l}^{-1}$. 


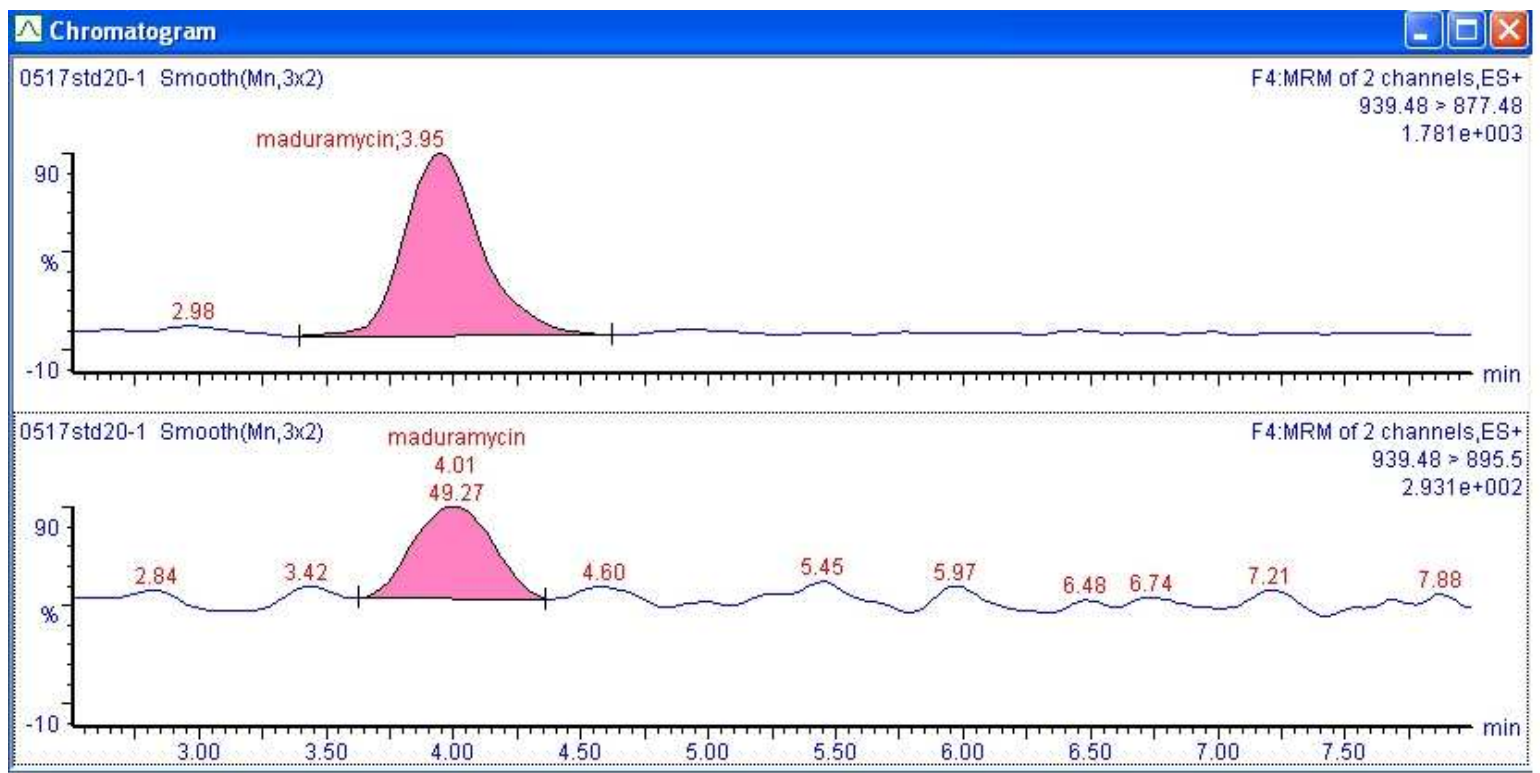

Figure 4. MRM chromatogram of maduramycin standard at the level of $20 \mu \mathrm{g} \cdot \mathrm{l}^{-1}$. 


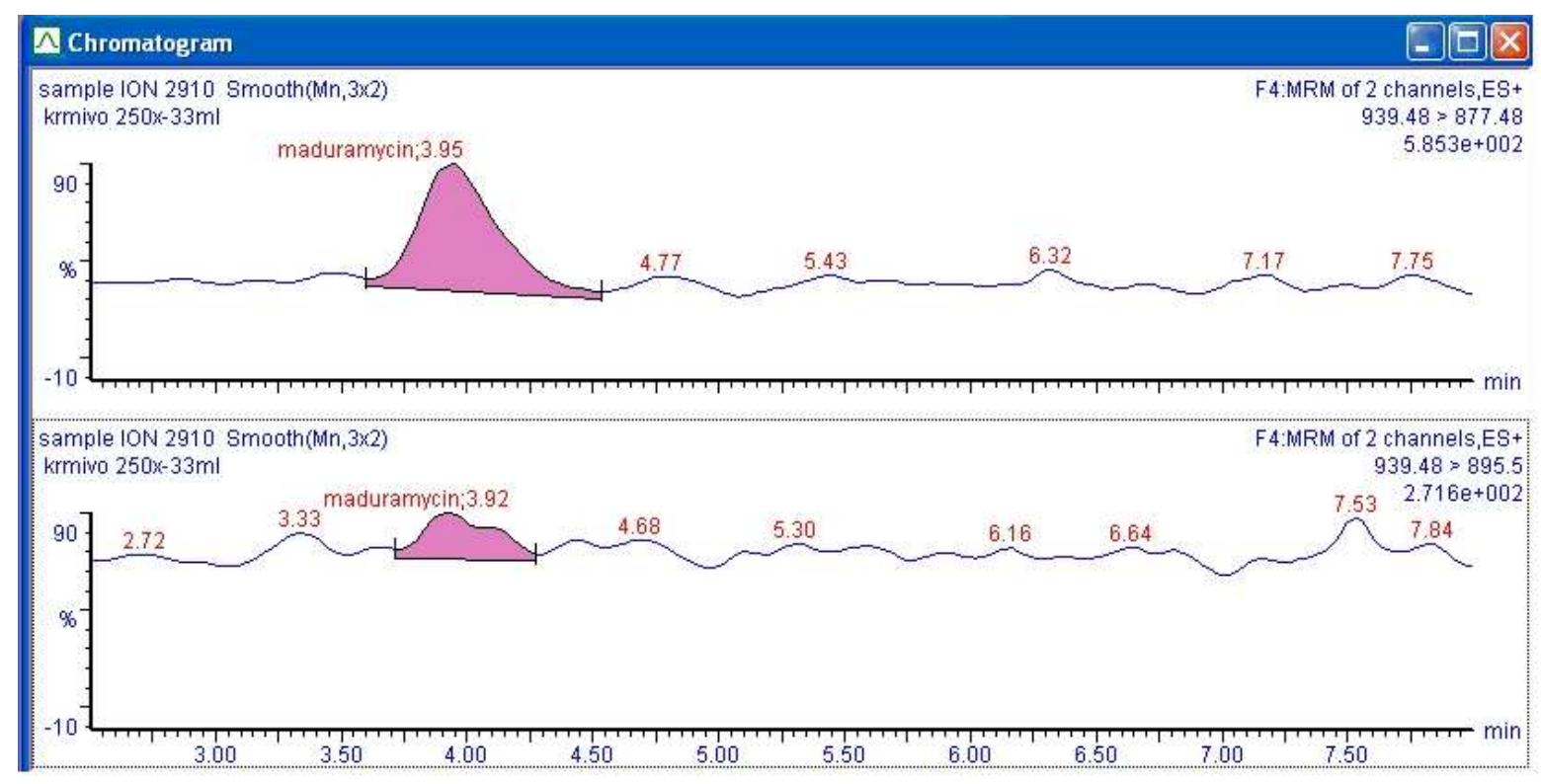

Figure 5. MRM chromatograms of feed sample containing maduramycin at the average concentration of $4.89 \mathrm{mg} \cdot \mathrm{kg}^{-1}$. 